\title{
Tolerância da mamoneira ao herbicida trifluralin em solos com diferentes texturas
}

\author{
Katty A. A. de L. Medeiros' ${ }^{1}$, Valdinei Sofiatti ${ }^{2}$, Humberto Silva ${ }^{3}$, \\ João H. Zonta ${ }^{2}$, Augusto G. F. Costa ${ }^{2} \&$ Joan B. Silva ${ }^{3}$
}

\begin{abstract}
RESUMO
A escassez de herbicidas registrados para a cultura da mamoneira ainda é fator limitante para sua expansão. Objetivou-se então, com este trabalho, avaliar a tolerância da mamoneira ao herbicida trifluralin em solos com diferentes texturas. O experimento foi conduzido em casa de vegetação, em delineamento inteiramente casualizado com cinco repetições, em esquema fatorial com 8 doses do herbicida trifluralin aplicado em pré-emergência $\left(0 ; 187,5 ; 375 ; 750 ; 1.500 ; 3.000 ; 6.000\right.$ e $12.000 \mathrm{~g} \mathrm{ha}^{-1}$ i.a.) e quatro tipos de substrato (areia lavada; franco-arenoso; franco argiloso-arenoso e franco-argiloso). Aos 28 dias após a semeadura foram determinadas as variáveis: altura de plantas, área foliar, massa seca da parte aérea, volume e massa seca do sistema radicular. Concluiu-se que a dose do herbicida trifluralin tolerada pela mamoneira é influenciada pelas características químicas e físicas do solo. Em solos de textura arenosa e franco-arenosa doses do herbicida trifluralin abaixo daquelas comumente utilizadas para controle de plantas daninhas, são suficientes para ocasionar redução no crescimento das plantas de mamoneira.
\end{abstract}

Palavras-chave: planta daninha, seletividade, Ricinus communis

\section{Tolerance of castor bean to trifluralin herbicide in soils of different textures}

\begin{abstract}
The scarcity of registered herbicides for cultivation of castor beans is still a limiting factor for its expansion. Thus, the aim of this study was to evaluate the tolerance of castor bean to trifluralin herbicide in soils of different textures. The experiment was conducted in a greenhouse in a completely randomized design with five replications in a factorial with 8 doses of the trifluralin herbicide $(0 ; 187.5 ; 375 ; 750 ; 1.500 ; 3.000$; 6.000 and $12.000 \mathrm{~g} \mathrm{ha}^{-1}$ i.a.) applied at pre-emergence and four types of substrates (washed sand; sandy loam; sandy clay loam; and clay loam soil). At 28 days after sowing, the variables plant height, leaf area, shoot dry weight, volume and dry mass of roots were measured. It was concluded that the tolerance of castor bean to trifluralin herbicide is influenced by chemical and physical characteristics of soil. In sandy and sandy loam soils, doses of trifluralin below those commonly used for weed control are sufficient to cause the decrease in the growth of castor bean plants.
\end{abstract}

Key words: weed, selectivity, Ricinus communis

\footnotetext{
${ }^{1}$ UEPB, Rua Baraúnas, 351, Bairro Universitário, CEP 58429-500, Campina Grande, PB. Fone: (83) 9638-9496. E-mail: kattyannee@gmail.com ${ }^{2}$ Embrapa Algodão, Rua Osvaldo Cruz 1143, Centenário, CEP 58428-095, Campina Grande, PB. Fone: (83) 3182-4300. E-mail: valdinei.sofiatti@embrapa.br; joao-henrique.zonta@embrapa.br; augusto.costa@embrapa.br

${ }^{3}$ Departamento de Ciências Biológicas/UEPB. Fone: (83) 3315-3300. E-mail: humbertoecologia@bol.com.br; bruno.brio@yahoo.com.br
} 


\section{INTRODUÇÃO}

Devido à sua tolerância ao déficit hídrico, a mamoneira (Ricinus communis L.) é cultivada no Nordeste; entretanto, esta cultura é muito sensível à interferência causada pelas plantas daninhas, sendo crítico o período que vai da emergência até os 40 aos 70 dias após a mesma, dependendo principalmente da cultivar, do espaçamento entre linhas de semeadura e das demais condições de cultivo (Azevedo et al., 2006; Maciel et al., 2007a). Neste período deve-se manter a cultura livre da competição com as plantas daninhas.

A utilização de herbicidas na cultura da mamoneira é o método mais prático e econômico de manejo das plantas daninhas, sobretudo para cultivos tecnificados em grandes áreas (Maciel et al., 2008), visto que o controle mecânico (principal método atualmente utilizado) é extremamente oneroso por necessitar de grande quantidade de mão-de-obra. Apesar dessas vantagens, para que mencionada prática possa ser utilizada, são necessários a identificação e estudos de herbicidas que sejam seletivos à cultura e que controlem eficientemente as plantas daninhas infestantes da área.

Na base de dados do Sistema de Agrotóxicos Fitossanitários (AGROFIT), do Ministério da Agricultura, Pecuária e Abastecimento, pode se constatar o saflufenacil como única opção de herbicida registrado para o controle de plantas daninhas na cultura da mamoneira, para utilização em pósemergência em jato dirigido (Brasil, 2013).

Maciel et al. (2007b) identificaram a seletividade à mamoneira dos herbicidas residuais pendimethalin, alachlor + pendimethalin e alachlor + trifluralin em aplicações de preplantio incorporado e de clomazone e clomazone + trifluralin aplicados em pré-emergência. Maciel et al. (2012) confirmaram a seletividade do herbicidas trifluralin e pendimethalin aplicados em pré-emergência de três cultivares de mamoneira, principalmente quando as sementes foram semeadas em profundidades entre 5 e $15 \mathrm{~cm}$. O herbicida trifluralin pertence ao grupo químico das dinitroanilinas e controla eficientemente plantas daninhas, gramíneas e algumas espécies dicotiledôneas de sementes pequenas (Raimondi et al., 2010; Sofiatti et al., 2012). Segundo Romam et al. (2007), as dinitroanilinas agem na divisão celular ligando-se ao microtúbulo no lugar da tubulina, interrompendo a síntese da fibra e, consequentemente, impedindo a divisão dos cromossomos, tendo como resultado a formação de células anormais. As dinitroanilinas não têm efeito na mitose de células animais, o que lhes confere baixa toxicidade ao homem e animais.

O método de controle químico das plantas daninhas com o uso de herbicidas geralmente é mais eficiente e econômico quando utilizado de forma racional, porém existem poucas informações para utilização dessa tecnologia na cultura. A seletividade dos herbicidas residuais está muito relacionada com a profundidade de semeadura e as características físicas e químicas do solo, pois estas alteram a capacidade de adsorção dos herbicidas no solo e, consequentemente, sua disponibilidade para o sistema radicular da planta (Silva et al., 2012).

Diante do exposto objetivou-se, com este trabalho, avaliar a tolerância da mamoneira ao herbicida trifluralin em solos com diferentes texturas.

\section{Material e Métodos}

O estudo foi realizado em condições de casa de vegetação,

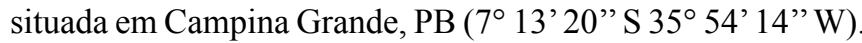
Para a pesquisa foram utilizados quatro tipos de substratos, sendo três solos coletados na camada de 0 a $20 \mathrm{~cm}$, provenientes da região de Itaporanga, $\mathrm{PB}\left(7^{\circ} 18^{\prime} 16^{\prime} \mathrm{S} 38^{\circ} 09^{\prime} 01 " \mathrm{~W}\right)$, Irecê, BA $\left(11^{\circ} 18^{\prime} 15^{\prime} \mathrm{S} 41^{\circ} 51^{\prime} 21^{\prime \prime} \mathrm{W}\right)$ e Barbalha, CE $\left(7^{\circ}\right.$ $\left.18^{\prime} 40^{\prime \prime} \mathrm{S} 39^{\circ} 18^{\prime} 15^{\prime \prime} \mathrm{W}\right)$, além da areia lavada, sendo esta tratada com ácido clorídrico para retirada de resíduos orgânicos presentes. Os solos foram classificados como Neossolo litólico, Cambissolo e Argissolo vermelho, respectivamente.

O experimento consistiu de oito doses do herbicida trifluralin $\left(0 ; 187,5 ; 375 ; 750 ; 1.500 ; 3.000 ; 6.000\right.$ e $12.000 \mathrm{~g} \mathrm{ha}^{-1}$ i.a. $)$ e quatro solos (arenoso; franco-arenoso; frango-argilosoarenoso; franco-argiloso), em delineamento inteiramente casualizado, com cinco repetições. As doses do herbicida foram determinadas obedecendo-se ao seguinte critério: $0,0 \mathrm{x} ; 0,125 \mathrm{x}$; $0,25 \mathrm{x} ; 0,5 \mathrm{x} ; 1 \mathrm{x} ; 2 \mathrm{x} ; 4 \mathrm{x}$ e $8 \mathrm{x}$, em que $\mathrm{x}$ - dose recomendada para outras culturas ( $1500 \mathrm{~g} \mathrm{ha}^{-1}$ i.a), conforme metodologia descrita por Seefeldt et al. (1995).

A caracterização química dos solos foi realizada no Laboratório de Solos e Nutrição de Plantas pertencente à Embrapa Algodão, conforme descrito por EMBRAPA (1997). Para análise textural os solos foram passados em peneira com malha de $2 \mathrm{~mm}$ e secados à sombra, de acordo com o descrito por EMBRAPA (1997) e em seguida classificados texturalmente no Laboratório de Irrigação e Salinidade (LIS) pertencente à Universidade Federal de Campina Grande (UFCG). Os resultados das análises físico-químicas são apresentados na Tabela 1.

O fósforo remanescente foi determinado em conformidade com a metodologia descrita por Alvarez V. \& Fonseca (1990) e a capacidade máxima de adsorção de fósforo para cada solo conforme metodologia descrita por Braga \& Defelipo (1974). Após a análise química fez-se o cálculo da adubação fosfatada

Tabela 1. Características físico-químicas dos substratos utilizados no estudo

\begin{tabular}{|c|c|c|c|c|c|c|c|c|c|c|c|c|c|c|c|}
\hline \multicolumn{12}{|c|}{ Características químicas } & \multicolumn{4}{|c|}{ Características físicas } \\
\hline \multirow{2}{*}{ Origem } & $\mathrm{pH}^{\mathrm{pH}}$ & $\mathrm{Ca}^{+2}$ & $\mathrm{Mg}^{+2}$ & $\mathrm{Na}^{+}$ & $\mathbf{K}^{+}$ & S & $\mathrm{H}^{+}+\mathrm{Al}^{3+}$ & $\mathbf{T}$ & \multirow{2}{*}{$\begin{array}{c}\text { V } \\
(\%)\end{array}$} & \multirow{2}{*}{$\begin{array}{l}\text { CMAP } \\
\text { mg g }^{-1}\end{array}$} & \multirow{2}{*}{$\begin{array}{l}\text { M.O. } \\
\text { g kg-1 }\end{array}$} & Areia & Silte & Argila & Classificação \\
\hline & $1: 2,5$ & \multicolumn{7}{|c|}{$\mathrm{mmol}_{\mathrm{c}} \mathrm{dm}^{-3}$} & & & & & (\%) & & \\
\hline Irecê-BA & 7,8 & 214,8 & 25,0 & 3,5 & 12,5 & 255,8 & 0,0 & 255,8 & 100 & 0,2975 & 23,9 & 71,68 & 2,83 & 25,49 & Franco-Argilo-Arenoso \\
\hline Barbalha-CE & 6,8 & 145,3 & 63,5 & 1,1 & 4,8 & 214,7 & 28,1 & 242,8 & 88 & 0,3954 & 20,9 & 45,01 & 23,48 & 31,51 & Franco-Argiloso \\
\hline Itaporanga-PB & 6,6 & 68,0 & 42,0 & 0,6 & 5,9 & 116,5 & 18,2 & 134,7 & 87 & 0,2793 & 15,9 & 72,64 & 13,80 & 13,56 & Franco-Arenoso \\
\hline Areia Lavada & 6,9 & 0,6 & 14,5 & 1,8 & 1,3 & 18,2 & 3,3 & 21,5 & 84 & - & 2,1 & 83,40 & 14,50 & 2,00 & Areia \\
\hline
\end{tabular}

${ }^{1} \mathrm{pH} \mathrm{H}_{2} \mathrm{O}$ - pH em água; $\mathrm{Ca}^{+2}$ - Cálcio; $\mathrm{Mg}^{+2}$ - Magnésio; $\mathrm{Na}^{+}$- Sódio; $\mathrm{K}^{+}$- Potássio; S - Soma de bases; $\mathrm{H}^{+}+\mathrm{Al}^{3+}$; -acidez potencial; $\mathrm{T}$ - Capacidade de troca catiônica; $\mathrm{V}$ - Saturação de bases; CMAP -Capacidade máxima de adsorção de fósforo; MO - Matéria orgânica 
dos solos. O potássio foi corrigido até $150 \mathrm{mg} \mathrm{dm}^{3} \mathrm{e}$ a adubação nitrogenada foi de $50 \mathrm{~g} \mathrm{de} \mathrm{N} \mathrm{m}^{-3}$ de solo. Para o substrato areia lavada não foi realizada adubação sendo utilizada a solução nutritiva de Hoagland completa preparada segundo Martinez \& Silva Filho (2006).

Os solos foram peneirados em peneira de malha $2 \mathrm{~mm}$ e misturados com adubo sendo posteriormente distribuídos em copos plásticos com capacidade para $500 \mathrm{~mL}$; após o preenchimento dos copos plásticos, a uma profundidade de $3,0 \mathrm{~cm}$, foram semeadas três sementes de mamona da cultivar BRS Energia por vaso; posteriormente, após irrigação inicial de $5 \mathrm{~mm}$, o herbicida trifluralin foi aplicado em pré-emergência, por meio de um pulverizador costal de precisão, pressurizado a $\mathrm{CO}_{2}$, munido de duas pontas de pulverização de jato plano 11002 espaçadas a $0,5 \mathrm{~m}$ entre si, na pressão constante de $2,0 \mathrm{kgf}$ pol $^{-2}$, a uma altura de $40 \mathrm{~cm}$ do alvo, proporcionando aplicação equivalente a $200 \mathrm{~L}$ de calda ha $^{-1}$.

A cada dois dias $20 \mathrm{~mL}$ da solução nutritiva de Hoagland completa foram aplicados ao substrato areia lavada, a fim de suprir os nutrientes essenciais ao crescimento das plantas. Para manutenção da umidade dos vasos, as irrigações foram realizadas três vezes ao dia, sempre na superfície dos recipientes, através de uma precipitação de $5 \mathrm{~mm} \mathrm{~d}^{-1}$, por meio de microaspersores. Sete dias após a aplicação do herbicida realizou-se o desbaste deixando-se apenas uma planta por recipiente.

Aos 28 dias após a aplicação (DAA) do herbicida trifluralin, o que correspondeu a 21 DAA, foram realizadas avaliações da altura da planta $(\mathrm{cm})$ e da área foliar $\left(\mathrm{cm}^{2}\right)$ de acordo com Severino et al. (2004). Posteriormente, as plantas foram cortadas na região do colo separando-se as raízes da parte aérea. $\mathrm{O}$ sistema radicular das plantas foi lavado em água corrente para eliminação do substrato. $\mathrm{O}$ volume do sistema radicular foi determinado seguindo metodologia descrita por Rocha et al. (2003) e Silva et al. (2006) na qual as raízes são lavadas em água corrente e colocadas em uma proveta graduada com volume de $100 \mathrm{~mL}$, contendo $50 \mathrm{~mL}$ de água em que, ao se adicionar as raízes determina-se o volume de água deslocado sendo este valor equivalente ao volume ocupado pelas raízes. Após este procedimento todo o material vegetal foi levado à estufa de ventilação forçada a $70^{\circ} \mathrm{C}$ por $72 \mathrm{~h}$ para posterior determinação da massa seca do sistema radicular e da parte aérea.

Os dados foram submetidos à análise de variância e de regressão não linear utilizando-se o modelo log-logístico de quatro parâmetros, conforme proposto por Seefeldt et al. (1995) e a Eq. 1.

$$
\hat{\mathrm{Y}}=\mathrm{f}(\mathrm{x})=\mathrm{C}+\frac{\mathrm{D}-\mathrm{C}}{1+\left(\frac{\mathrm{x}}{\mathrm{I}_{50}}\right)^{\mathrm{b}}}=\mathrm{C}+\frac{\mathrm{D}-\mathrm{C}}{1+\exp \left[\mathrm{b}\left(\log (\mathrm{x})-\log \left(\mathrm{I}_{50}\right)\right)\right]}
$$

em que:

D - limite superior da curva

C - limite inferior da curva

B - declividade da curva

$\mathrm{I}_{50} \quad$ - dose que proporciona $50 \%$ de redução no crescimento da cultura

O limite superior da curva $(\mathrm{D})$ corresponde à resposta média da testemunha e o limite inferior da curva $(\mathrm{C})$ é a resposta média com altas doses de herbicida. $O$ parâmetro $b$ descreve a declividade da curva em torno do $\mathrm{I}_{50}$. A partir das curvas ajustadas pelo modelo foi calculado o $\mathrm{I}_{50}$ (dose de trifluralin que proporcionou $50 \%$ de inibição no crescimento da mamoneira) para cada solo.

\section{Resultados E Discussão}

A análise de variância indicou diferenças significativas para os tipos de solo e doses do herbicida trifluralin para todas as variáveis avaliadas (Tabela 2). Desta forma, foram ajustadas curvas de dose resposta utilizando-se o modelo log-logístico de quatro parâmetros como preconizado por Seefeldt et al. (1995) para cada solo, sendo calculadas as doses do herbicida que ocasionaram a redução de $50 \%$ do crescimento $\left(\mathrm{I}_{50}\right)$ das plantas nos solos avaliados (Tabela 2). Observa-se que as doses suportadas pelas plantas de mamoneira foram influenciadas pelas características químicas e físicas dos diferentes solos, sendo os valores de $I_{50}$ decrescentes na seguinte ordem, independente da variável: solos de textura franco-argilosa $>$ franco-argilo-arenosa $>$ franco-arenosa $>$ arenosa.

Para o substrato areia lavada, doses menores do herbicida trifluralin, em relação aos demais substratos, causaram inibição de $50 \%$ no crescimento da mamoneira cujos valores de $\mathrm{I}_{50}\left(\mathrm{~g}\right.$ i. a. ha $\left.{ }^{-1}\right)$ corresponderam a 728,9 $\left(\mathrm{AL}_{50}\right), 683,5\left(\mathrm{AF}_{50}\right), 439,0\left(\mathrm{MSPA}_{50}\right)$, 3361,8 $\left(\mathrm{MSSR}_{50}\right)$ e 3696,0 $\left(\mathrm{VSR}_{50}\right)$ - (Tabela 3 e Figuras 1 a 5, respectivamente). Esta resposta se deve, provavelmente, ao fato de que este substrato possui baixo teor de matéria orgânica e argila (Tabela 1), o que ocasionou pouca adsorção do herbicida e, em contrapartida, proporcionou maior disponibilidade do mesmo na solução do solo. Além disso, solos arenosos em razão da elevada porosidade entre partículas (macroporosidade), possuem alta condutividade hidráulica enquanto solos argilosos, com espaços diminutos entre suas partículas (menor macroporosidade), têm condutividade hidráulica apreciavelmente menor o que reduz a difusão do herbicida no solo (Taiz \& Zeiger, 2004). Em seus estudos, Pires et al. (1997) também constataram, com o herbicida trifluralin na cultura do sorgo em diversos solos, menores doses de herbicida necessárias à redução de $50 \%$ no crescimento das

Tabela 2. Resumo da análise de variância para as variáveis de crescimento altura (AL), área foliar (AF), massa seca da parte aérea (MSPA), massa seca do sistema radicular (MSSR) e volume do sistema radicular (VSR)

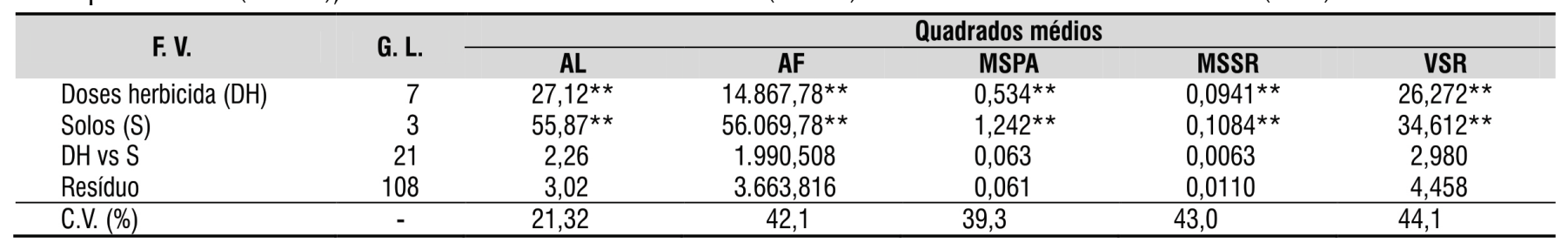

F.V. - fontes da variaçãa; G.L. - grau de liberdade; ** - significativo a 0,01 de probabilidade pelo teste F; C.V.(\%) - coeficiente de variação 
plantas no substrato areia lavada. Os autores ainda afirmam que a areia é um material inerte e não tem capacidade de adsorver herbicida; portanto, a diferença entre o $I_{50}$ da areia e os $I_{50}$ dos outros substratos é ocasionada pela quantidade do herbicida trifluralin adsorvida aos coloides do solo. Esses resultados corroboram com os obtidos por Maciel et al. (2012), que verificaram que a mamoneira semeada em solo arenoso a $2,5 \mathrm{~cm}$ de profundidade submetido à aplicação do herbicida trifluralin na dose de $1.125 \mathrm{~g} \mathrm{ha}^{-1}$ i.a. apresentou reduções no diâmetro do caule em uma das cultivares estudadas.

As doses do herbicida trifluralin calculadas que inibiram $50 \%$ do crescimento em altura das plantas (Figura 1), área foliar (Figura 2) massa seca de parte aérea (Figura 3) e massa seca (Figura 4) e volume de raízes (Figura 5) foram maiores no solo classificado como franco-argiloso em relação aos demais com valores de $\mathrm{I}_{50}$ que corresponderam, respectivamente, a: 4969,8; 4743,$6 ; 4257,1 ; 6161,2$ e 5033,5 $\mathrm{g} \mathrm{ha}^{-1}$ (Tabela 3). É provável que este solo tenha apresentado maior sorção do herbicida trifluralin, deixando-o menos disponível para absorção via solução do solo.

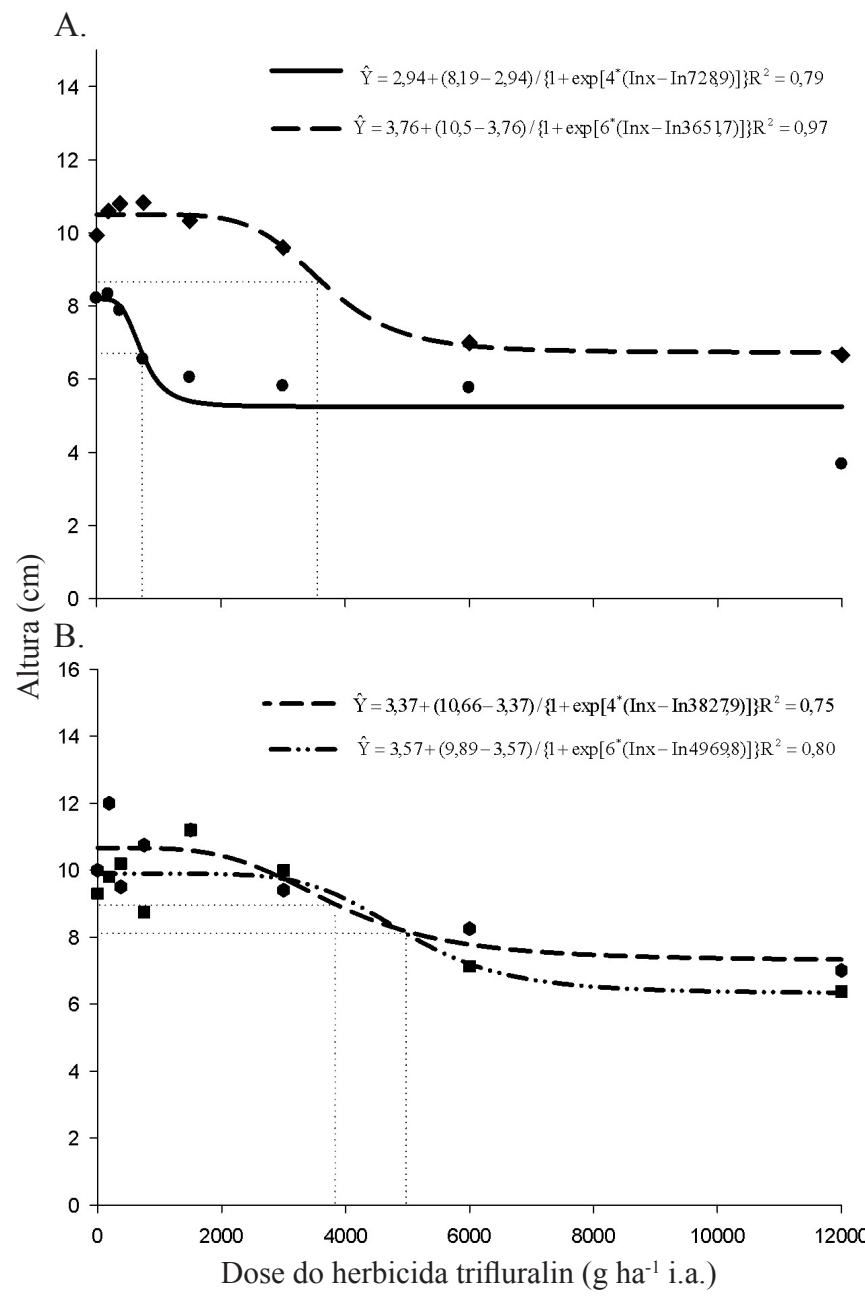

Figura 1. Curvas de dose-resposta do herbicida trifluralin referente à altura das plantas da mamoneira cultivada nos solos arenoso (- -), franco-arenoso $\left.(-)^{-}\right)(\mathrm{A})$; franco-argiloso-arenoso (----) e francoargiloso (B) $\left(-{ }^{-}-\right)$, aos 28 dias após a aplicação do herbicida

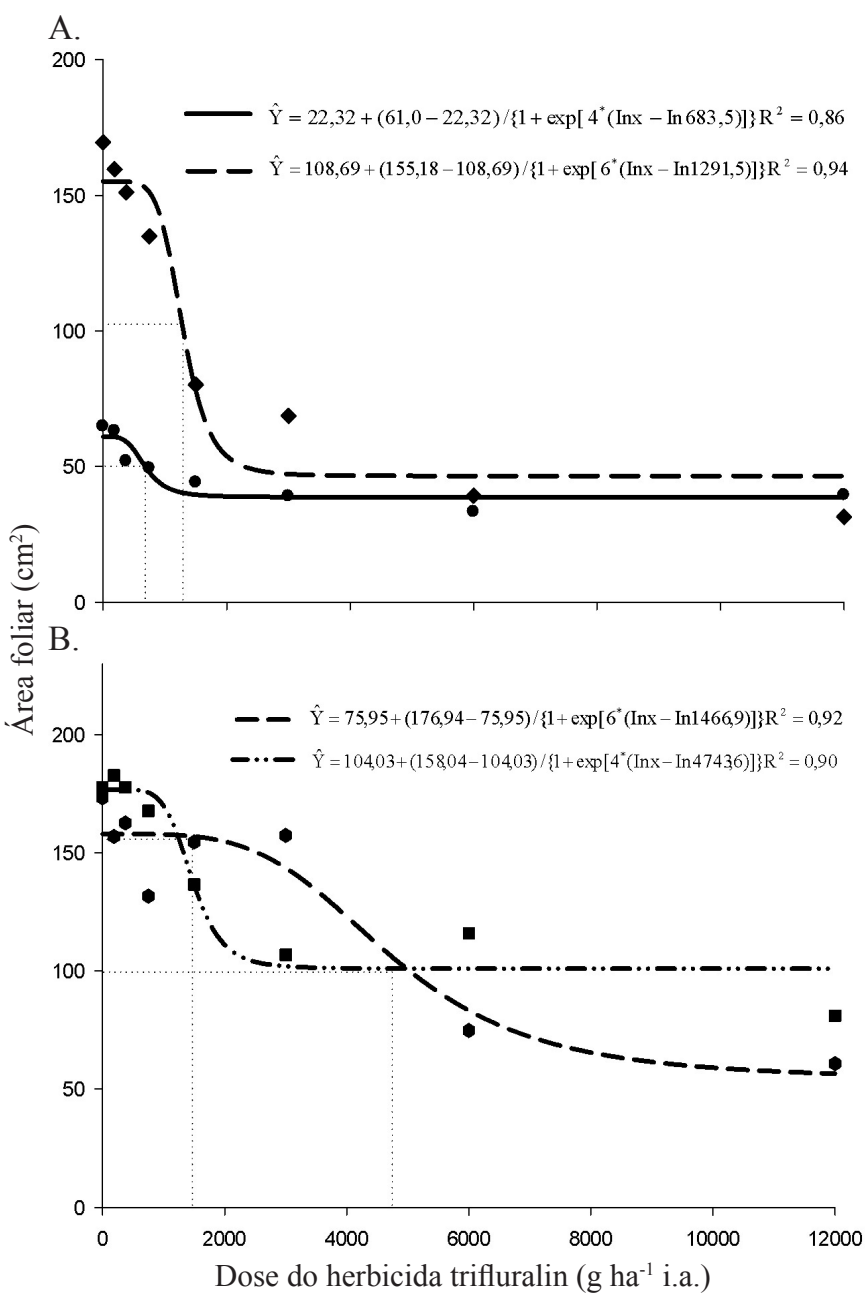

Figura 2. Curvas de dose-resposta do herbicida trifluralin referente à área foliar da mamoneira cultivada nos solos arenoso (- -), franco-arenoso $(--)$ (A); franco-argiloso-arenoso (----) e francoargiloso (B) (- " - $)$; aos 28 dias após a aplicação do herbicida

Comparativamente aos solos arenoso e franco-argiloso, valores intermediários de $\mathrm{I}_{50}$ foram detectados para o solo franco-argilo-arenoso, seguidos daqueles obtidos com o franco-arenoso. Para o primeiro substrato as doses (g i.a.ha ${ }^{-1}$ ) para redução de $50 \%$ da altura, área foliar, massa seca de parte aérea, massa seca e volume de raízes, foram de $3.827,9 ; 1.466,9$; $2.942,0 ; 4.504,6$ e $4.677,7$ e para o segundo, de 3651,$7 ; 1291,5$; 1053,$5 ; 3960,0$ e 4215,4 , respectivamente. Corroborando esses resultados, Firmino et al. (2008) constataram que as doses do imazapyr que causaram $50 \%$ de inibição da produção de massa seca da planta-teste apresentaram a seguinte ordem decrescente entre os substratos avaliados: muito argiloso $>$ franco-argiloarenoso $>$ areia-franca $>$ areia lavada. Ainda conforme os autores, a sorção de herbicidas na superfície dos colóides orgânicos e minerais do solo explica parte do comportamento apresentado por essas moléculas, dentro das diversas classes de solo, tornando-se difícil predizer o comportamento dos herbicidas sem antes conhecer os fatores que agem sobre eles. Diante disto, é possível afirmar que as características físicoquímicas do substrato e, consequentemente, sua classificação textural, irão influenciar os teores de herbicida disponíveis para 


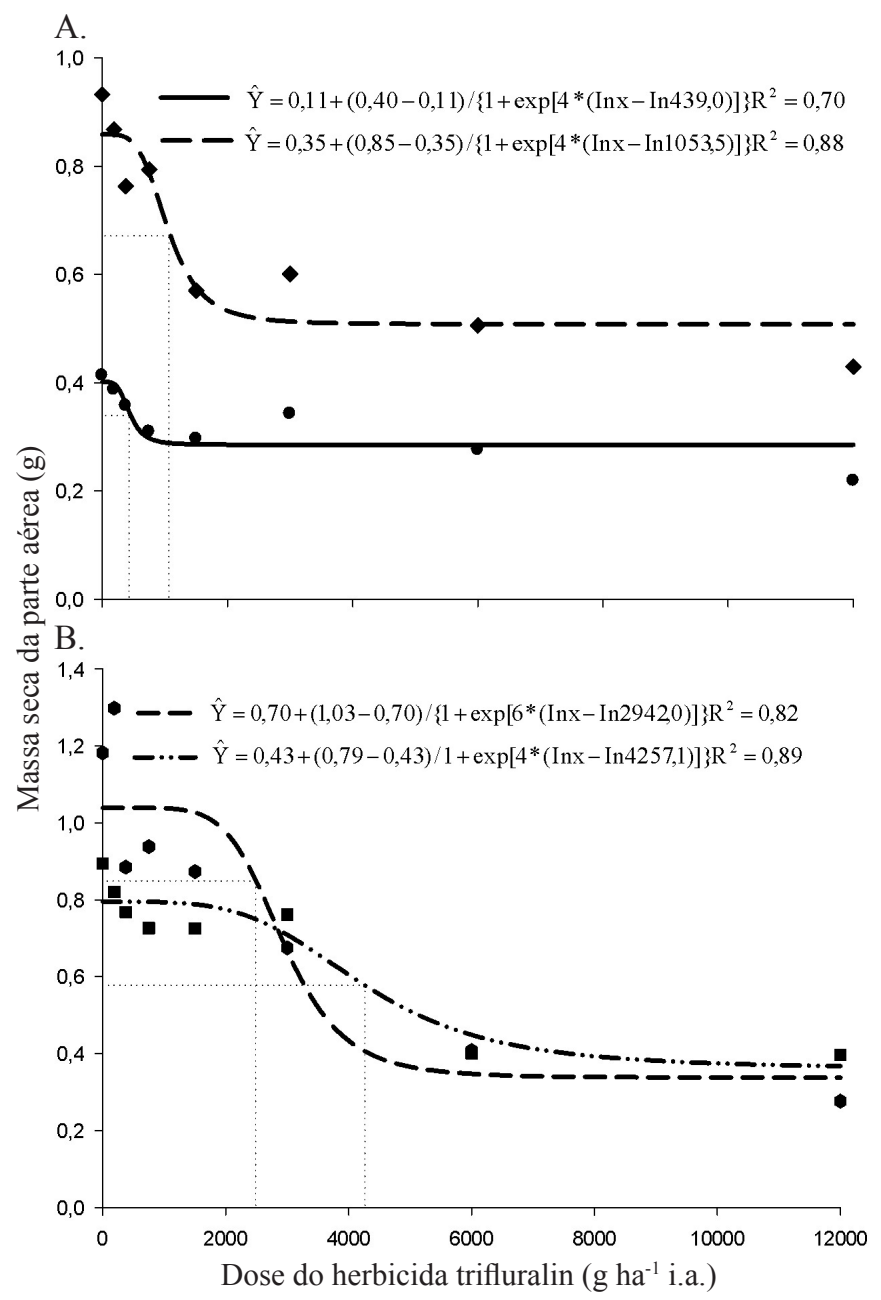

Figura 3. Curvas de dose-resposta do herbicida trifluralin referente à massa seca da parte aérea da mamoneira cultivada nos solos arenoso (- -), franco-arenoso (- -) (A); franco-argiloso-arenoso (---) e franco-argiloso (B) (- - - -); aos 28dias após a aplicação do herbicida

absorção da planta. Para as variáveis massa seca do sistema radicular (Figura 4) e volume do sistema radicular (Figura 5), os resultados confirmaram o verificado para as variáveis de crescimento da parte área (Figuras 1 a 3); entretanto, ressalta-se que a redução de $50 \%$ do crescimento do sistema radicular foi constatada em doses consideravelmente mais altas do herbicida comparadas àquelas necessárias para redução da parte aérea. Mesmo que o sistema radicular não tenha apresentado redução acentuada no crescimento, a redução na altura, na área foliar e na massa seca da parte área, pode ter ocorrido pela translocação

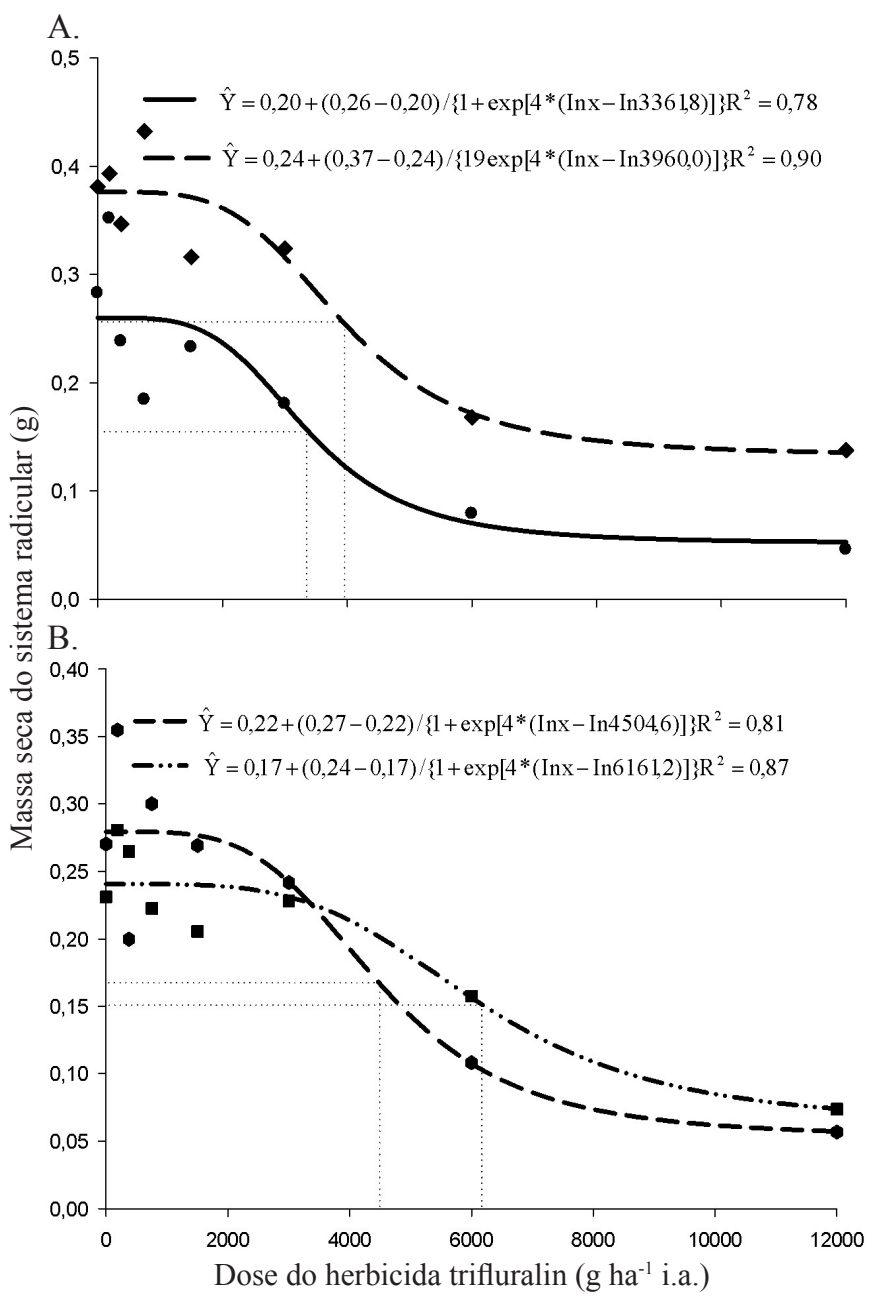

Figura 4. Curvas de dose-resposta do herbicida trifluralin referentes à massa seca do sistema radicular da mamoneira cultivada nos solos arenoso ( - -), franco-arenoso (- -) (A); franco-argiloso-arenoso (----) e franco-argiloso (B) (- ${ }^{-*}-$ ); aos 28dias após a aplicação do herbicida

do herbicida reduzindo-se a divisão celular da parte aérea e consequentemente seu crescimento.

Sanchonete et al. (2010) observaram, ao estudar a seletividade do herbicida pré-emergente clomazone em arroz irrigado, que em solos com textura arenosa e baixo teor de matéria orgânica a fitotoxicidade foi maior comparativamente ao solo de textura argilosa e com maior teor de matéria orgânica. Silva et al. (2012) também verificaram que o herbicida pendimethalin causa fitotoxidez na cultura da mamoneira em baixas doses quando o solo apresenta baixos teores de argila e

Tabela 3. Dose calculada do herbicida trifluralin que ocasionou $50 \%$ de inibição do crescimento em altura $\left(\mathrm{AL}_{50}\right)$, área foliar $\left(\mathrm{AF}_{50}\right)$, massa seca da parte aérea $\left(\mathrm{MSPA}_{50}\right)$, massa seca do sistema radicular $\left(\mathrm{MSSR}_{50}\right)$ e volume do sistema radicular $\left(\mathrm{VSR}_{50}\right)$ em função do substrato

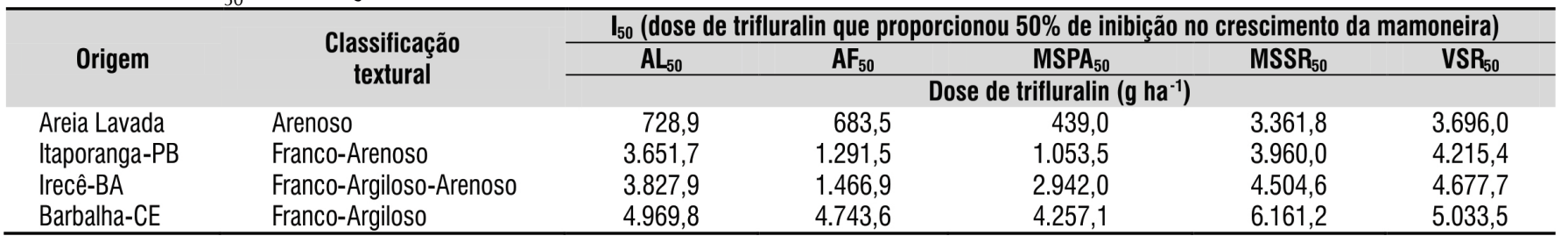




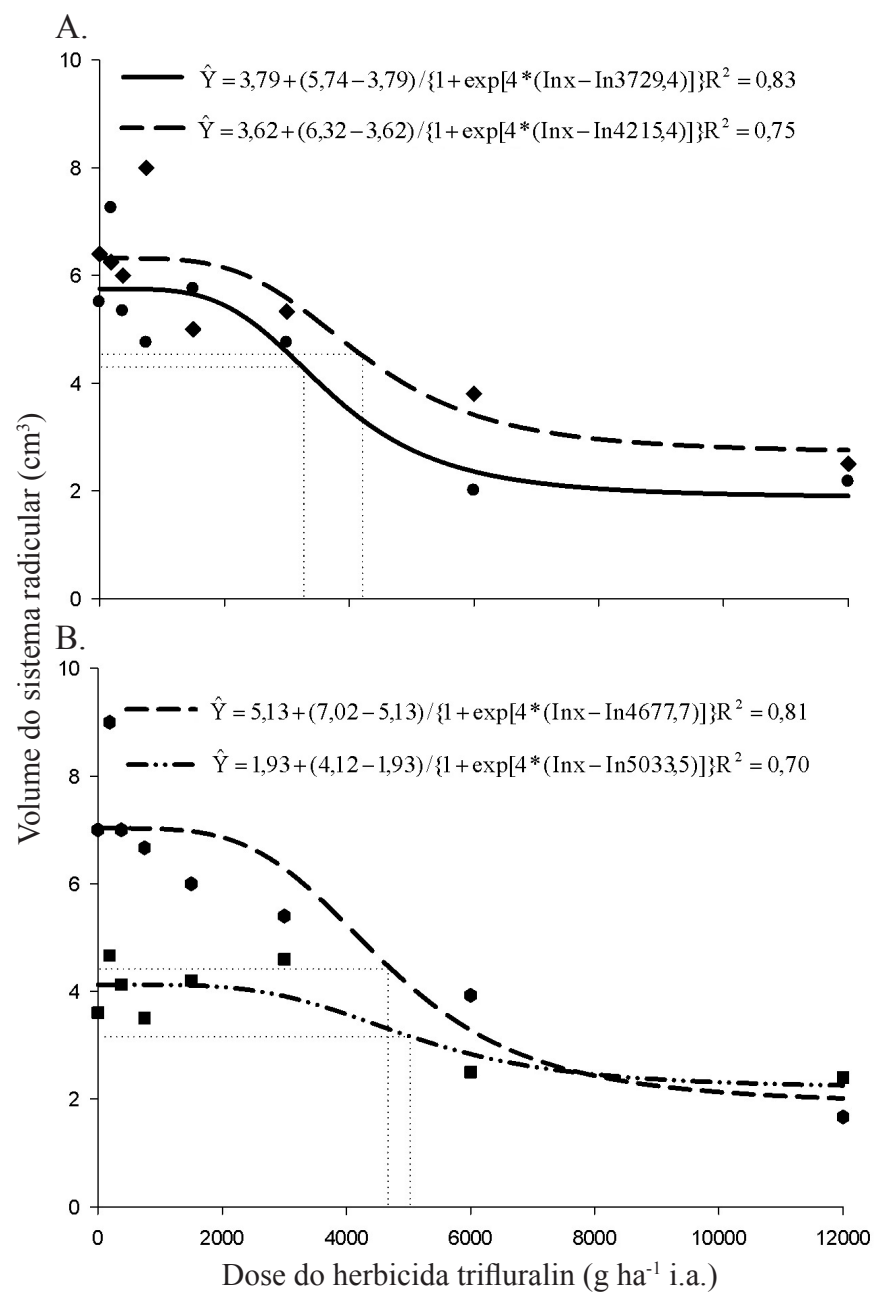

Figura 5. Curvas de dose-resposta do herbicida trifluralin referente ao volume do sistema radicular da mamoneira cultivada nos solos arenoso (- -), Franco-Arenoso (- - ) (A); Franco-Argiloso-Arenoso (---) e Franco-Argiloso (B) (_.. -); aos 28 dias após a aplicação do herbicida

matéria orgânica. Esses resultados são semelhantes aos obtidos no presente estudo com o herbicida trifluralin, demonstrando também que o efeito biológico dos herbicidas pré-emergentes tem alta correlação com a textura e a matéria orgânica do solo.

Em geral, os resultados constatados revelam que a redução no crescimento das plantas da mamoneira depende das características químicas e físicas do solo. Em solos de textura arenosa, baixas doses são suficientes para reduzir o crescimento inicial da parte aérea das plantas, mesmo que o sistema radicular seja pouco afetado. As doses do herbicida trifluralin normalmente utilizadas para o controle de plantas daninhas são de no máximo $1.500 \mathrm{~g} \mathrm{ha}^{-1}$ i.a., o que, na maioria dos solos, não causa reduções consideráveis no crescimento das plantas; entretanto, para solos de textura arenosa e franco-arenosa esta dose deve ser reduzida uma vez que pode causar fitotoxidez e redução do crescimento das plantas de mamoneira.

\section{CONCLUSÕES}

1. A dose do herbicida trifluralin tolerada pela mamoneira é influenciada pelas características químicas e físicas do solo.
2. Em solos de textura arenosa e franco-arenosa, doses do herbicida trifluralin abaixo daquelas comumente utilizadas para controle de plantas daninhas são suficientes para ocasionar redução no crescimento das plantas de mamoneira.

\section{Literatura Citada}

Alvarez V., V. H.; Fonseca, D. M. Definição de doses de fósforo para determinação da capacidade máxima de adsorção de fosfatos para ensaios em casa de vegetação. Revista Brasileira de Ciência do Solo, v.14, p.49-55, 1990.

Azevedo, D. M. P.; Santos, J. W. dos; Santos, T. S.; Leão, A. B. Manejo de plantas daninhas na cultura da mamoneira. Campina Grande: Embrapa Algodão, 2006. 6p. Comunicado Técnico, 274

Braga, J. M.; Defelipo, B. V. Determinação espectrofotométrica de fósforo em extratos de solo e material vegetal. Revista Ceres, v.21, p.73-85, 1974.

EMBRAPA - Empresa Brasileira de Pesquisa Agropecuária. Centro Nacional de Pesquisa de Solos. Manual de métodos de análise de solos. 2.ed. Rio de Janeiro: EMBRAPA, 1997. 212p.

Firmino, L. E.; Santos, L. D. T.; Ferreira, F. A.; Ferreira, L. R.; Tibúrcio, R. A. S. Sorção do imazapyr em solos com diferentes texturas. Planta Daninha, v.26, p.395-402, 2008.

Maciel, C. D. de G; Poletine, J. P.; Velini, E. D.; Amaral, J. G. C.; Zani, L. P.; Santos, R. F.; Rodrigues, M.; Raimondi, M. A.; Ribeiro, R. B. Possibilidade de aplicação de misturas de herbicidas de ação total com jato dirigido em mamoneira de porte anão. Planta Daninha, v.26, p.457-464, 2008.

Maciel, C. D. de G; Poletine, J. P.; Velini, E. D.; Zanotto, M. D.; Amaral, J. G. C.; Santos, H. R.; Artioli, J. C.; Silva, R. R. M.; Ferreira, R. V.; Lolli, J.; Raimondi, M. A. Períodos de interferência de plantas daninhas sobre características de desenvolvimento da mamoneira savana. Revista Brasileira de Oleaginosas e Fibrosas, v.11, p.23-29, 2007a.

Maciel, C. D. de G.; Poletine, J. P.; Velini, E. D.; Zanotto, M. D.; Amaral, J. G. C. do; Santos, H. R. dos; Artioli, J. C.; Silva, T. R. M. da; Ferreira, R. V.; Lolli, J.; Raimondi, M. A. Seletividade de herbicidas em cultivares de mamona. Revista Brasileira de Oleaginosas e Fibrosas, v.11, p.47-54, 2007b.

Maciel, C. D. de G.; Poletine, J. P.; Velini, E. D.; Zanotto, M. D.; Florentino, R. S.; Zani, L. P.; Cruz, M. C. Desenvolvimento de cultivares de mamoneiras em relação à profundidade de semeadura e seletividade de herbicidas dinitroanilinas. Semina: Ciências Agrárias, v.33, p.27-38, 2012.

MAPA - Ministério da Agricultura, Pecuária e Abastecimento, Brasil. Sistema AGROFIT. <http://extranet.agricultura.gov.br/ agrofit_cons/principal_agrofit_cons $>.01$ Ago. 2013.

Martinez, H.E.P.; Silva Filho, J.B. Introdução ao cultivo hidropônico de plantas. 3.ed. Viçosa: UFV, 2006. 111p.

Pires, N. de M.; Silva, J. F.; Silva, J. B.; Ferreira, L. R.; Cardoso, A. A. Adsorção e lixiviação de trifluralin e imazaquin em diferentes solos. Revista Ceres, v.44, p.300-314, 1997.

Raimondi, M. A.; Oliveira Jr, R. S.; Constantin, J.; Biffe, D. F.; Arantes, J. G. Z.; Franchini, L. H.; Rios, F. A.; Blainski, E.; Osipe, J. B. Atividade residual de herbicidas aplicados ao solo em relação ao controle de quatro espécies de Amaranthus. Planta Daninha, v.28, p.1073-1085, 2010. 
Rocha, M. R.; Mota, W. F. da; Pereira, M. C. T.; Magalhães, V. R.; Tarchetti, G. P.; Alves, F. G.; Gonçalves, R. E. M.; Pereira, E. K. C. Tecnologia alternativa para a produção de mudas de abóbora com a utilização de substrato orgânico. Unimontes Científica, v.5, p.1-12, 2003.

Romam, E. S.; Beckie, H.; Vargas, L.; Hall, L.; Rizzardi, M. A.; Wolf, T. Como funcionam os herbicidas: da biologia à aplicação. Passo Fundo: Berthier, 2007. $159 \mathrm{p}$.

Sanchotene, D. M.; Kruse, N. D.; Avila, L. A.; Machado, S. L. O.; Nicolodi, G. A.; Dornelles, S. H. B. Phorate e dietholate protegem o arroz da fitotoxicidade do clomazone em doses elevadas. Planta Daninha, v.28, p.909-912, 2010.

Seefeldt, S. S.; Jensen, J. E.; Fuerst, E. P. Log- Logistic analysis of herbicide dose - response relationships. Weed Technology, v.9, p.218-227, 1995.
Severino, L. S.; Cardoso, G. D.; Vale, L. S. do; Santos, J. W. dos. Método para determinação da área foliar da mamoneira. Revista Brasileira de Oleaginosas e Fibrosas, v.8, p.753-762, 2004.

Silva, K. C.; Silva, V. N. B.; Sofiatti, V.; Zonta, J. H.; Lima, R. L. S.; Silva, H. Tolerância de mamoneira ao herbicida pendimethalin em solos com diferentes capacidades de adsorção. Revista Brasileira de Engenharia Agrícola e Ambiental, v.16, p.1298-1304, 2012.

Silva, M. T. H.; Martins, A. B. G.; Andrade, R. A. Enraizamento de estacas de pitaya vermelha em diferentes substratos. Revista Caatinga, v.19, p.61-64, 2006.

Sofiatti, V.; Severino, L. S.; Silva, F. M. de O.; Silva, V. N. B.; Brito, G. G. Pre and post emergence herbicides for weed control in castor crop. Industrial Crops and Products, v. 37 , p.235-237, 2012.

Taiz, L.; Zeiger, E. Fisiologia vegetal. 3.ed. Porto Alegre: Artmed, 2004. 722p. 